Article

\title{
Lifetime Analysis of Commercial 3 W UV-A LED
}

\author{
F. Jose Arques-Orobon ${ }^{1, *(\mathbb{D})}$, Manuel Vazquez ${ }^{1,2}$ (D) and Neftali Nuñez ${ }^{1,2, *(\mathbb{D})}$
}

1 Escuela Técnica Superior de Ingeniería y Sistemas de Telecomunicación, Universidad Politécnica de Madrid, 28031 Madrid, Spain; manuel.vazquez@upm.es

2 Instituto de Energía Solar, Universidad Politécnica de Madrid, 28040 Madrid, Spain

* Correspondence: jose.arques@upm.es (F.J.A.-O.); neftali.nunez@upm.es (N.N.)

Received: 27 September 2020; Accepted: 18 November 2020; Published: 27 November 2020

\begin{abstract}
The lifetime of ultraviolet high-power light-emitting diodes (UV HP-LEDs) is an open issue due to their high current density, high temperature, and UV radiation. This work presents a reliability study and failure analysis of three high-temperature accelerated life tests (ALTs) for 13,500 h with $3 \mathrm{~W}$ commercial UV LEDs of $365 \mathrm{~nm}$ at a nominal current in two working conditions: continuous mode and cycled mode ( $30 \mathrm{~s}$ on/30 s off). Arrhenius-Weibull parameters were evaluated, and an equation to evaluate the lifetime (B50) at any junction temperature and other relevant lifetime functions is presented. The Arrhenius activation energy was $0.13 \mathrm{eV}$ for the continuous mode and $0.20 \mathrm{eV}$ for the cycled mode. The lifetime at $50 \%$ survival and $30 \%$ loss of optical power as a failure definition, working at $\mathrm{T}_{\mathrm{a}}=40^{\circ} \mathrm{C}$ with a multi-fin heat sink in natural convection, was over $4480 \mathrm{~h}$ for the continuous mode and 19,814 $\mathrm{h}$ for the cycled mode. The need to add forced convection for HP-LED arrays to achieve these high-reliability values is evidenced. The main source of degradation is the semiconductor device, and the second is the encapsulation silicone break.
\end{abstract}

Keywords: UV LED; lifetime; reliability; accelerated life test; optoelectronic; substrates

\section{Introduction}

The market and applications of ultraviolet high-power light-emitting diodes (UV HP-LEDs) have rapidly increased in the last years. Optical efficiency, a simpler power supply, eco-friendly characteristics, and the use of a simpler power supply of UV HP-LEDs have led to their preference over ultraviolet lamps, introducing other new applications [1-4]. UV LEDs have lower power per device, from less than one watt to a few tens of watts, compared to lamps used in industrial applications, ranging from a few to 3000 watts [5]. The "Status of the Solid-State Lighting Source Industry, 2019" report by Yole Développement [6] identified that in 2018, the UV light source market share was 74.7\% UV lamps and 25.3\% UV LEDs, with a total market share of over USD 0.2 billion, which could more than double to USD 0.5 billion in 2024.

In this work, we developed temperature accelerated life tests (ALTs) to analyze the lifetime of a commercial $3 \mathrm{~W}, 365 \mathrm{~nm}$ UV LED with the high external quantum efficiency of UV LEDs [7]. The applications of UV-A LEDs with wavelengths from 320 to $400 \mathrm{~nm}$ include resin curing, photocatalytic water and air purification [8], high-resolution microscopes, industrial inspection, fluorescence light [9], biological research [10], sanitary radiation for sterilization and disinfection [11], and printing.

To determine the lifetime and compare commercial UV-A HP-LEDs and UV lamps, it is necessary to consider the definitions of two parameters:

- Failure: For LED light sources, the LM-80 standard [12] defines failure time, Lx, as the time the light's lumen maintains $\mathrm{x} \%$ of its initial value measured in nominal conditions, and the typical level for illumination purposes is the maintenance of 70\% lumen (L70). In the case of 
mercury xenon lamps for industrial applications, it maintains 50\% of its initial value (L50), a less demanding condition.

- Lifetime: The American National Standards Institute/Illuminating Engineering Society (ANSI/IES) RP-16 [13] defines the lifetime parameter B50 as the time when 50\% of lamps have not failed while the other $50 \%$ have failed. From a reliability point of view, $R_{(B 50)}=0.5$ and $F_{(B 50)}=1-R_{(B 50)}=0.5$, where $\mathrm{R}_{(\mathrm{B} 50)}$ is the reliability at $t=\mathrm{B} 50 \mathrm{~h}$ and $F_{(B 50)}$ the unreliability. These parameters can be directly applied to the UV LED lifetime, although in semiconductor devices, it is more common to use the mean time to failure (MTTF), defined as the expected time to failure for a nonrepairable device. The MTTF for these devices is larger than B50, albeit with comparable values [14].

In this work, we assess lifetime considering the B50 period and define the most demanding condition, L70, as a failure for UV LEDs (B50L70). This lifetime is compared with the less demanding definition used for the standard lifetime of industrial mercury xenon lamps (B50L50), between 500 and $5000 \mathrm{~h}[5]$.

The main issues affecting the lifetime of AlGaN-based UV LEDs are electrical stress due to a high-density current $[3,15]$, thermal management of the package with a very small chip volume, degradation of the lens system under high temperature and UV radiation [16], and the quality of the growth substrate. Sapphire is currently the primary substrate of AlGaN-based UV-A LEDs due to the range of wavelength applications, large size, and cost [1]. However, sapphire is not an ideal substrate because the large lattice mismatch between $\mathrm{GaN}$ and sapphire substrates usually induces high-stress and high-density dislocations, consequently degrading the optical performance of UV LEDs. Due to this problem, there is intensive research to improve sapphire substrates and develop new substrate materials $[1,4,7,16-20]$. In our opinion, removing or laser-lifting the GaN crystal of the grown substrate can be a solution for high-technology devices such as multijunction solar cells or some lasers [7]; however, for commercial UV-A LEDs, the interface improvement with the GaN crystal growth is probably the more implemented solution [19] for economic reasons.

UV-A LED reliability tests have focused on high-temperature studies at a nominal or high current stress to reduce the test time $[16,17]$. The main target of these ALTs is to evaluate lifetime and identify the main weaknesses and failures [21]. However, there are few works in the literature that evaluate the complete parameters of the Arrhenius-Weibull model in temperature ALTs [14]. These tests require complex, expensive, and time-consuming instrumentation; however, new, cheaper ALT lifetime evaluation methods that require less time are emerging [22-25]. A complete analysis is required to develop the classical three high-temperature ALTs in nominal working conditions [14].

This work presents the results and discussion of three temperature accelerated lifetime tests (ALTs) with a total time of $13,500 \mathrm{~h}$. The device used is a commercial $3 \mathrm{~W}$ GaN-based high-power $365 \mathrm{~nm}$ UV LED in two working conditions: continuous mode and cycled mode ( $30 \mathrm{~s}$ on/30 s off). The influence of natural and forced convection is also analyzed and evaluated.

Section 2 presents descriptions of the device and temperature ALTs and thermal measurements of the working and dissipation conditions. Section 3 is divided into four subsections: experimental temperature ALT, evaluation of lifetime parameters for natural convection from ALT, evaluation of lifetime parameters at forced convection, and failure analysis. Section 4 discusses the results and focuses on the applications, limitations, and generalizations of commercial UV-A LEDs.

\section{Materials and Methods}

The analyzed LED is a commercial $3 \mathrm{~W}, 365 \mathrm{~nm}$ nominal peak-wavelength with $700 \mathrm{~mA}$ $\left(\mathrm{J} \approx 60 \mathrm{~A} / \mathrm{cm}^{2}\right)$ maximum forward current and power of $900 \mathrm{~mW}$. The LEDs were tested at $600 \mathrm{~mA}$ $\left(\mathrm{J} \approx 51 \mathrm{~A} / \mathrm{cm}^{2}\right.$ ) current injection ( $85 \%$ of maximum), with a supply over $2.3 \mathrm{~W}$ and a dissipation power over $1.5 \mathrm{~W}$. The measured average peak-wavelength of the tested LEDs was $369.63 \mathrm{~nm} \pm 0.25 \mathrm{~nm}$, which is into the tolerance identified by the manufacturer. This commercial UV-A LED has one of the leading high power packages [18], with a low junction-ambient thermal resistance of $4.2{ }^{\circ} \mathrm{C} / \mathrm{W}$ and a 
maximum junction temperature $\left(T_{j}\right)$ of $150{ }^{\circ} \mathrm{C}$ [18] and, due to its characteristics, is frequently used in research applications [26-28].

Figure 1a shows the assembly of the UV LED during ALTs. The LED is set over a standard $19.9 \mathrm{~mm}$ diameter star-shaped metal core printed circuit board (PCB) with a protection device (Figure 1b). This circuit adheres with thermal tape to a high fin density heat sink that is $40 \mathrm{~mm}(\mathrm{~L}) \times 40 \mathrm{~mm}(\mathrm{~W}) \times 18 \mathrm{~mm}(\mathrm{H})$ in size (BGA-STD-115, ABL Components ${ }^{\circledR}$ ) (Figure 1a). Thermal simulation of this setup with another UV LED model can be seen in previous work [29]. As shown in Figure 1c, the previous assembly was placed under a Sanyo Denki fan (Ref. 9GA0412P3J011) that is $40 \mathrm{~mm}(\mathrm{~L}) \times 40 \mathrm{~mm}(\mathrm{~W}) \times 28 \mathrm{~mm}(\mathrm{H})$ in size, supplied at $11.5 \mathrm{~V}$, to evaluate the influence of forced convection on the lifetime parameters.

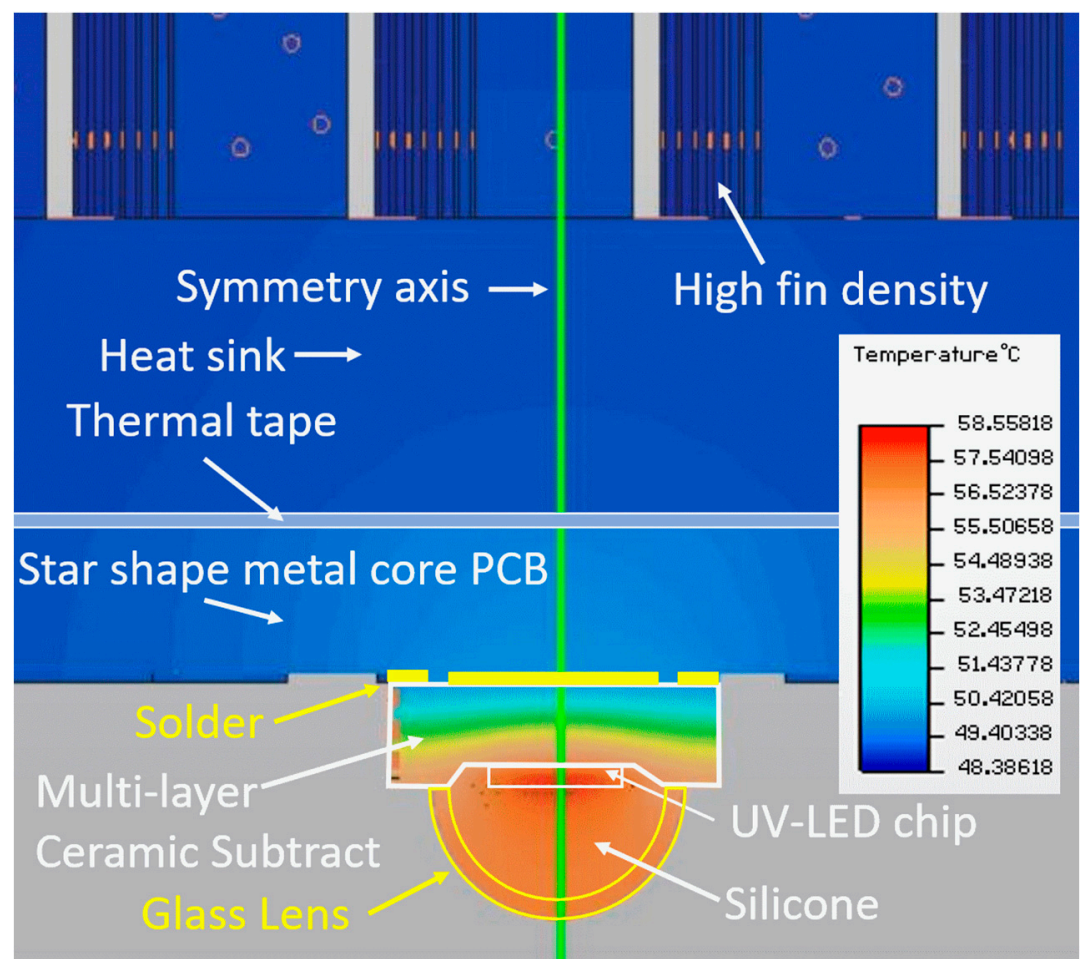

(a)

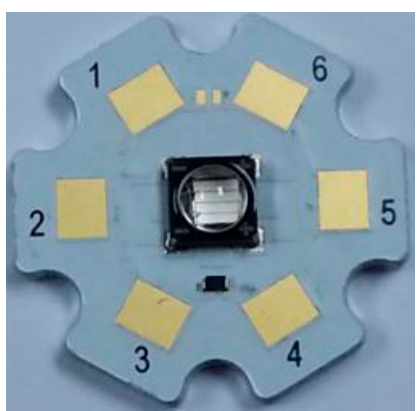

(b)

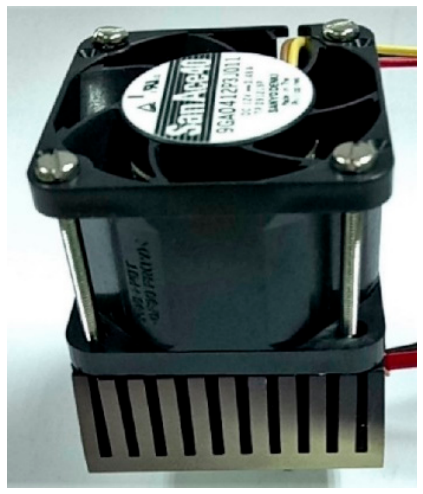

(c)

Figure 1. (a) Diagram and thermal simulation results $\left(\mathrm{T}_{\mathrm{a}}=40{ }^{\circ} \mathrm{C}\right)$ of the high power ultraviolet light-emitting diode in a natural convection configuration: $\mathrm{LED}$, star-shaped metal core printed circuit board (MCPCB), thermal tape, and heat sink; (b) photograph of the star-shaped MCPCB with the UV LED in the center and black protection device below; (c) photograph of the UV LED in a forced configuration, with a fan over the heat sink.

Temperature ALT under nominal working conditions is a common method to evaluate the lifetime of optoelectronic devices in a short period of time. The advantage of temperature ALT is that the lifetime is accelerated, and the acceleration factor due to high temperature can be evaluated from the ALT results by applying the Arrhenius-Weibull model [14,22-25,30].

For the temperature ALTs, 13 LEDs were used at different temperatures and working conditions. A LED without a current injection was loaded into the $90{ }^{\circ} \mathrm{C}$ chamber as a control reference, and the other 12 LEDs were tested under two working conditions, continuous and cycled, the latter with a 50\% duty cycle of $30 \mathrm{~s}$ on and $30 \mathrm{~s}$ off. In applications such as curing, the continuous working mode is more advantageous than cycled, because for the same dose of UV energy, roughly half the working time is needed. However, in applications such as fluorescent light sources, UV radiation is required for short time periods, as in the cycled mode. This prompted our interest in comparing both working modes. For these temperature ALTs, three climatic chambers at 60,75 , and $90{ }^{\circ} \mathrm{C}$ ambient temperature with 
UV-A LEDs under natural convection conditions were used. In each chamber, two LEDs in continuous and two LEDs in cycled working conditions were tested with current injection.

The UV-A LEDs were characterized inside and outside the climatic chamber by means of different techniques:

- Inside the climatic chamber. An automatic data acquisition system controlled with LabView ${ }^{\mathrm{TM}}$ periodically measured the current voltage (I-V) curve of each LED every $8 \mathrm{~h}$ to identify semiconductor degradation during the test, as well as catastrophic failures. Due to the different UV LED junction temperatures $\left(T_{j}\right)$, the I-V curves cannot be directly compared between UV-A LEDs of different chambers.

- Outside the climatic chamber. I-V curves and optical power output evolution at different wavelengths at a controlled temperature of $25 \pm 0.5^{\circ} \mathrm{C}$ and natural convection were measured. These measurements were initially performed more frequently, and later once a week. For I-V curves, a four-wire system controlled by a LabVIEW program with a $61 / 2$ bit digital multimeter and a precision power supply was used. For optical output power, a USB MIGHTEX ${ }^{\mathrm{TM}}$ mini-spectrometer with a charge-coupled device (CCD) of 3648 pixels and a resolution of $9 \mathrm{~nm}$ was used.

The duration of each temperature ALT was $4470 \mathrm{~h}$. For LEDs working in cycled mode, the net operating time was half of this ( $2235 \mathrm{~h}$ ). For most industrial applications, the cumulative UV energy is the key. For that, except for graphs of temperature ALT results, the extrapolation of lifetime in cycled mode was developed with net operating time for a more realistic comparison of continuous versus cycled mode.

Two failure modes were considered: catastrophic and output optical power degradation failure. In catastrophic failure, the optical power abruptly decays to zero, and degradation failure is defined as the time when the optical power falls to $70 \%$ of its initial value (L70).

In order to measure the UV-A LED junction temperature $\left(T_{j}\right)$, a method that uses the I-V curve as a temperature sensor was developed to characterize it under the four working conditions of continuous and cycled (30 s on/30 s off) in natural and forced convection at $25 \pm 0.5^{\circ} \mathrm{C}$ ambient temperature. To evaluate the lifetime, all measurements and results were extrapolated to ambient temperature, $\mathrm{T}_{\mathrm{a}}=40^{\circ} \mathrm{C}$, because it is a more realistic working condition (Figure 2).

The procedure to measure $T_{j}$ is described in other papers [25,29,31], and in Joint Electron Device Engineering Council (JEDEC) standards JESD-51-14 and JESD-51-51. This method uses the real time measurement of forward voltage at a low current versus temperature to infer $T_{j}$.

Figure 2 presents the $T_{j}$ evolution with time, for an ambient temperature of $40^{\circ} \mathrm{C}$. The stabilized measured results are listed in Table 1.

From Figure 2, at $\mathrm{T}_{\mathrm{a}}=40^{\circ} \mathrm{C}$, two performance levels for each dissipation feature can be identified. In natural convection there is $4{ }^{\circ} \mathrm{C}$ of difference between $T_{j}$ in continuous and cycled during on mode, while in forced convection, both $T_{j}$ values are similar at the maximum temperature. These relative $T_{j}$ values over $40^{\circ} \mathrm{C}$ ambient temperature will remain constant at other ambient temperatures, because all of the thermal parameters of the materials and conditions are relatively similar over the typical $\mathrm{T}_{\mathrm{a}}$ operation range. The period of stabilization is $15 \mathrm{~min}$ for natural convection and $1 \mathrm{~min}$ for forced convection.

Table 1 describes the relative $T_{j}$ values over $\mathrm{T}_{\mathrm{a}}$ and absolute $T_{j}$ values at $\mathrm{T}_{\mathrm{a}}=40^{\circ} \mathrm{C}$.

From Table 1 we can see a general improvement in $T_{j}$ in cycled mode with respect to continuous mode in natural convection, and a significant drop in the $T_{j}$ temperature between natural and forced convection.

The ambient temperature $\left(T_{a}\right)$ is the common factor in the comparison of the two working modes, but to extrapolate lifetime working in other environmental and dissipation conditions, the specific $T_{j}$ measured in real working conditions is needed to identify the lifetime periods and parameters, with the equations given in the results section. 


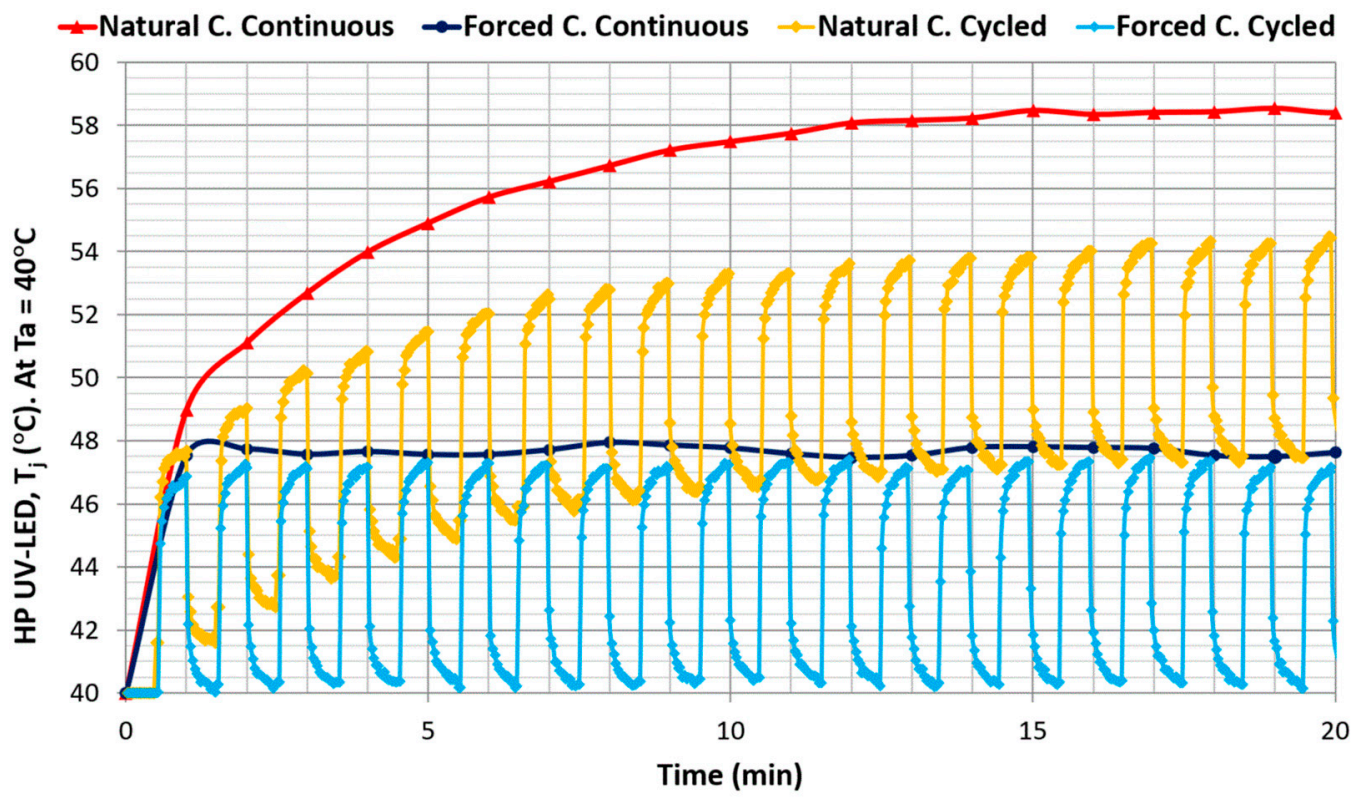

Figure 2. The junction temperature $\left(T_{j}\right)$ of the UV LED was measured at $\mathrm{T}_{\mathrm{a}}=40{ }^{\circ} \mathrm{C}$ for natural convection and forced convection, and for the continuous and cycled (30 s on/30 s off) working modes. Continuous and cycled $T j$ under natural convection is shown in red and orange; $T_{j}$ under forced convection is shown in light and dark blue.

Table 1. Increased $T j$ of UV LED over any ambient temperature value, and absolute $T j$ value for $\mathrm{T}_{\mathrm{a}}=40^{\circ} \mathrm{C}$, in natural and forced convection and continuous and cycled working mode.

\begin{tabular}{|c|c|c|}
\hline Convection Type & $\begin{array}{c}\text { Continuous Working } \\
\Delta T_{j} \text { over } \mathrm{T}_{\mathrm{a}} / T_{j\left(\mathrm{Ta}=40^{\circ} \mathrm{C}\right)}\left({ }^{\circ} \mathrm{C}\right)\end{array}$ & $\begin{array}{c}\text { Cycled Working } \\
\Delta T_{j} \text { over } \mathrm{T}_{\mathrm{a}} / T_{j\left(\mathrm{Ta}=40^{\circ} \mathrm{C}\right)}\left({ }^{\circ} \mathrm{C}\right)\end{array}$ \\
\hline Natural Convection & $18.5 / 58.5$ & $14.5 / 54.5$ \\
\hline Forced Convection & $7.5 / 47.5$ & $7 / 47$ \\
\hline
\end{tabular}

\section{Results}

The results obtained in this section are the lifetime parameters of this commercial $3 \mathrm{~W}$ UV-A LED related to the $T_{j}$ and $\mathrm{T}_{\mathrm{a}}$ for two working conditions: continuous and cycled working. Furthermore, all the Arrhenius-Weibull model parameters were obtained.

The lifetime for the condition B50L70 (a 50\% population failure below 70\% of the original optical power) is estimated at 19,814 $\mathrm{h}$ for cycled working; this supposes $9907 \mathrm{~h}$ of real working time and $4488 \mathrm{~h}$ for continuous work. The addition of forced convection reduces the working $T_{j}$ temperature and increases by $7.7 \%$ the lifetime for cycled working. The failure mode of this UV-A LED is the loss of optical power output to under $70 \%$ of the initial condition. The causes of failure are mainly the degradation of the semiconductor, and encapsulation silicone degradation.

In Section 3.1, we present the optical power degradation curves of UV-A LEDs under high-temperature ALT at nominal current, working under two working conditions. The instant of defined failure $(70 \%)$ was identified by these curves or extrapolated for cycled mode, which has a low degradation slope that does not exceed the failure limit.

In Section 3.2, we develop the calculus of the Arrhenius-Weibull model parameters as a function of $T_{j}, T_{a}$, and the working conditions, using the maximum likelihood estimation (MLE) method. The parameters obtained are the activation energy $\left(E_{A}\right)$ and acceleration factor $\left(A_{F}\right)$ equation of the Arrhenius model, and the $\beta$ and $\eta$ parameters of the Weibull curve. The obtained results are compared with the bibliographic related to UV LED ALTs, and we conclude that the parameters are coherent with previous publications when they can be compared. 
In Section 3.3, we evaluate the lifetime parameters in forced convection, obtaining the reliability equations of the forced system and the increase in lifetime values, which demonstrate that forced convection is only interesting for arrays of HP UV-LEDs.

In Section 3.4, we develop the failure analysis basis in optical power degradation measurement, I-V curves, and the encapsulation optical inspection. The results are in line with the previous bibliography, with two contributions to degradation: the semiconductor and the silicone material of encapsulation.

In the results section, we consider $\mathrm{T}_{\mathrm{a}}=40^{\circ} \mathrm{C}$, a common UV LED operation under real conditions, which is compared mainly with the results of temperature ALT at $\mathrm{T}_{\mathrm{a}}=60^{\circ} \mathrm{C}$. This test temperature does not suppose excessive overstress with respect to the nominal $\mathrm{T}_{\mathrm{a}}=40^{\circ} \mathrm{C}$, and for that, the performance will be similar.

\subsection{Experimental Temperature ALT Results}

The main results of the tests are as follows:

- None of the 12 UV LEDs with nominal current injection suffered catastrophic failure.

- The 12 UV LEDs had a progressive degradation of optical power during temperature ALT.

- The reference UV LED, tested without current injection at $90{ }^{\circ} \mathrm{C}$, had negligible optical power degradation. No I-V curve degradation or visible silicone encapsulant degradation was observed at the end of the test.

The six LEDs tested in nominal continuous working mode (two for each ambient temperature ALT) failed due to degradation of optical power to under 70\% (L70) of the initial value. The six LEDs tested in cycled working mode, with only half the time of real-time operating, did not fail by degradation during the ALT period; the worst performance occurred at $90^{\circ} \mathrm{C}$, where the average cycled UV LEDs had roughly 75\% optical power at the end of the test.

Figure 3 shows the normalized optical power evolution of the four LEDs at $\mathrm{T}_{\mathrm{a}}=60^{\circ} \mathrm{C}$ : two in continuous working mode with $T_{j}=78.5^{\circ} \mathrm{C}$, and two in cycled working mode with $T_{j}=74.5^{\circ} \mathrm{C}$. The degradation in the other tests, at 60 and $90^{\circ} \mathrm{C}$, showed the same tendency, and from that, it is possible to identify the average instant of failure (L70) for continuous working mode. However, for cycled working mode, it was necessary to extrapolate the instant of failure, because the degradation was under the failure limit. The Reliasoft ${ }^{\circledR}$ Weibull++/ALTA software (accelerated life testing data analysis software tool) has the option of loading optical power curve degradation, identifying the last slope tendency and prolonging it, using different types of curve tendencies (lineal, exponential, etc.) and deciding the best option by MLE, thereby obtaining the failure instantly. The values of each LED instant of failure were included in the Arrhenius-Weibull software information data to identify the parameters.

The average instant of test time failure by degradation (L70) can be seen in Table 2. Failure time in the cycled working mode was roughly four times that in continuous working mode, but the net-working time was only double.

\subsection{Evaluation of Lifetime Parameters in Natural Convection}

The Arrhenius-Weibull model for temperature ALT [14] is the model used to determine lifetime in nominal working current conditions at any $\mathrm{T}_{\mathrm{a}}$ of operation with a specific sink and fan, or specific $T_{j}$ in other real working conditions. The common procedure to corroborate this model is to use three ALT temperatures to obtain a good fit of the Arrhenius model for any time parameter of the test, such as $\mathrm{B} 50, \eta$, or mean time to failure (MTTF) for the three temperatures.

The Weibull distribution model can identify the parameters of any reliability test, because it can model any of the three parts in the typical bathtub curve: early mortality, constant random failures, and wear-out failures. The link with the Arrhenius model is that parameter $\eta$ (location parameter of Weibull) has a different value for each particular LED junction temperature, $\eta_{(\mathrm{Tj})}$, and has a good fit 
for the three tests using the Arrhenius model, while $\beta$ (shape parameter of Weibull) is invariant with temperature [14].

Once both Weibull parameters are assessed, we know $f(t)$, the failure probability density function:

$$
f(t)=\frac{\beta}{\left(\eta_{(T j)}\right)^{\beta}}(t)^{\beta-1} e^{-\left(\frac{t}{\left.\eta_{(T j}\right)}\right)^{\beta}},
$$

where $f(t)$ can be calculated for any $T_{j}$ temperature. We used $T_{j}$ because it is a generalized parameter; it is possible to use $\mathrm{T}_{\mathrm{a}}$ for the specific dissipation conditions of these tests, or $T_{j}$ for any other working conditions of this UV HP-LED, as the respective $T_{j}$ in forced convection. $\beta$ is the Weibull shape parameter, which depends only on the main type of failure acceleration in time, and $\eta_{(T j)}$ is the Weibull location parameter, which has temperature dependence. The cumulative failure probability at the location parameter is $0.632\left(F\left(\eta_{(T j)}\right)=0.632\right)$, which means that at this instant of time $63.2 \%$ of the population has failed.

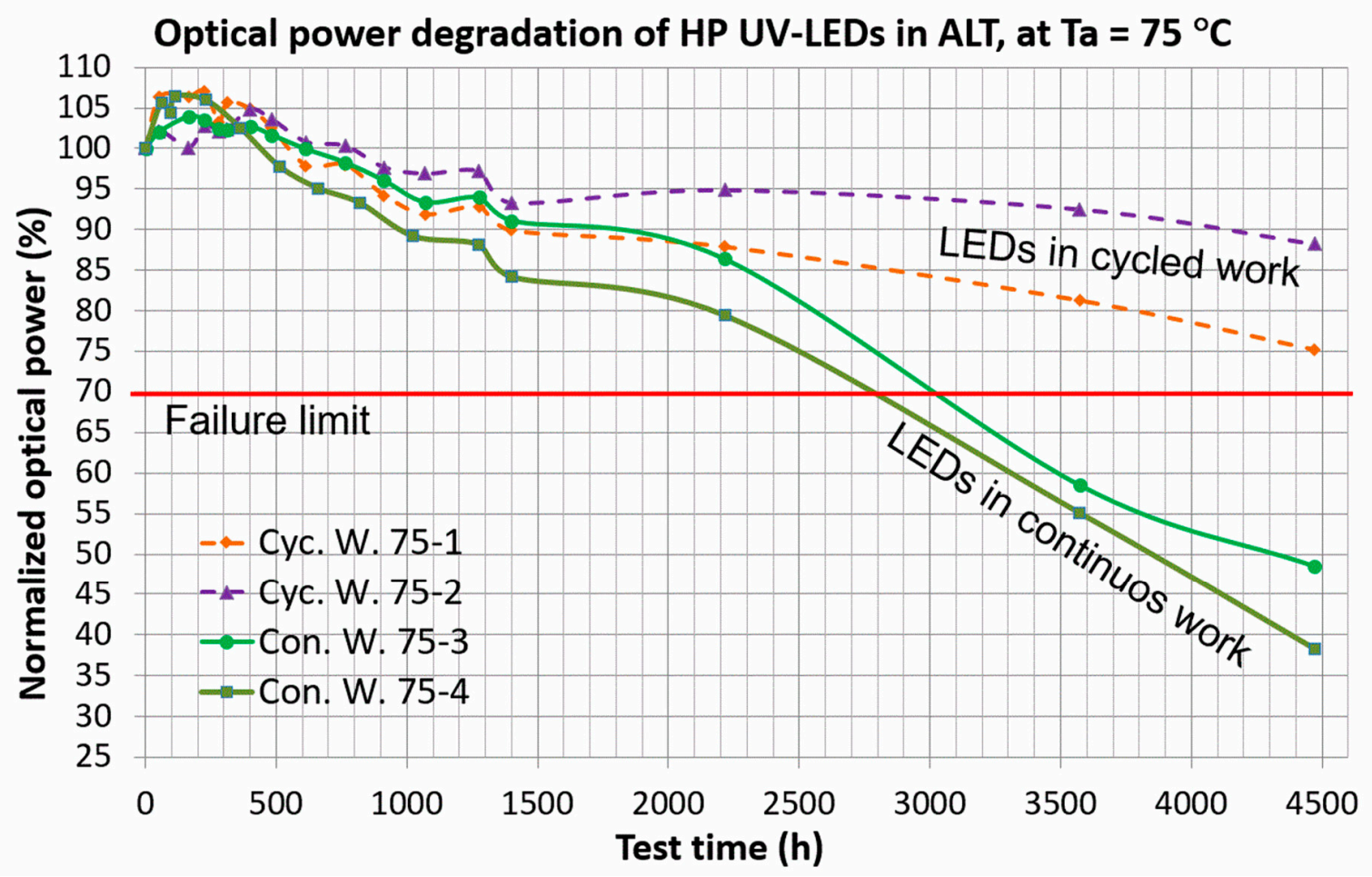

Figure 3. Normalized optical power evolution of four UV LEDs tested at $\mathrm{T}_{\mathrm{a}}=75^{\circ} \mathrm{C}$ in temperature accelerated life tests (ALTs). LEDs in continuous working mode (Con. W.) are indicated by a continuous line; UV LEDs in cycled working mode (30 s on/30 s of) (Cyc. W.) are indicated by a dashed line. In the figure, 75-1 to 75-4 are the IDs of the UV LEDs.

Table 2. Average instant of failure of temperature accelerated tests and working conditions. Values indicate time in the climatic chamber. ${ }^{*}$ Cycled working condition failure instant was extrapolated.

\begin{tabular}{ccc}
\hline Working Conditions & Continuous Working (h) & Cycled Working (h) \\
\hline $\mathrm{T}_{\mathrm{a}}=60^{\circ} \mathrm{C}$ & 3235 & ${ }^{\circ} 12,337$ \\
$\mathrm{~T}_{\mathrm{a}}=75^{\circ} \mathrm{C}$ & 2851 & ${ }^{\circ} 10,251$ \\
$\mathrm{~T}_{\mathrm{a}}=90^{\circ} \mathrm{C}$ & 2313 & $* 6732$ \\
\hline
\end{tabular}

In Figure 4, the gray area shows the $f(t)$ evaluation curve for each ALT in natural convection, $\mathrm{T}_{\mathrm{a}}$, and working conditions. The green line indicates the $\eta_{(T a)}$ for continuous working, and the red line for 
cycled working. The two dashed black lines aid the identification of $\eta_{(\mathrm{Ta})}$ for ambient temperature at 25 and $40{ }^{\circ} \mathrm{C}$.

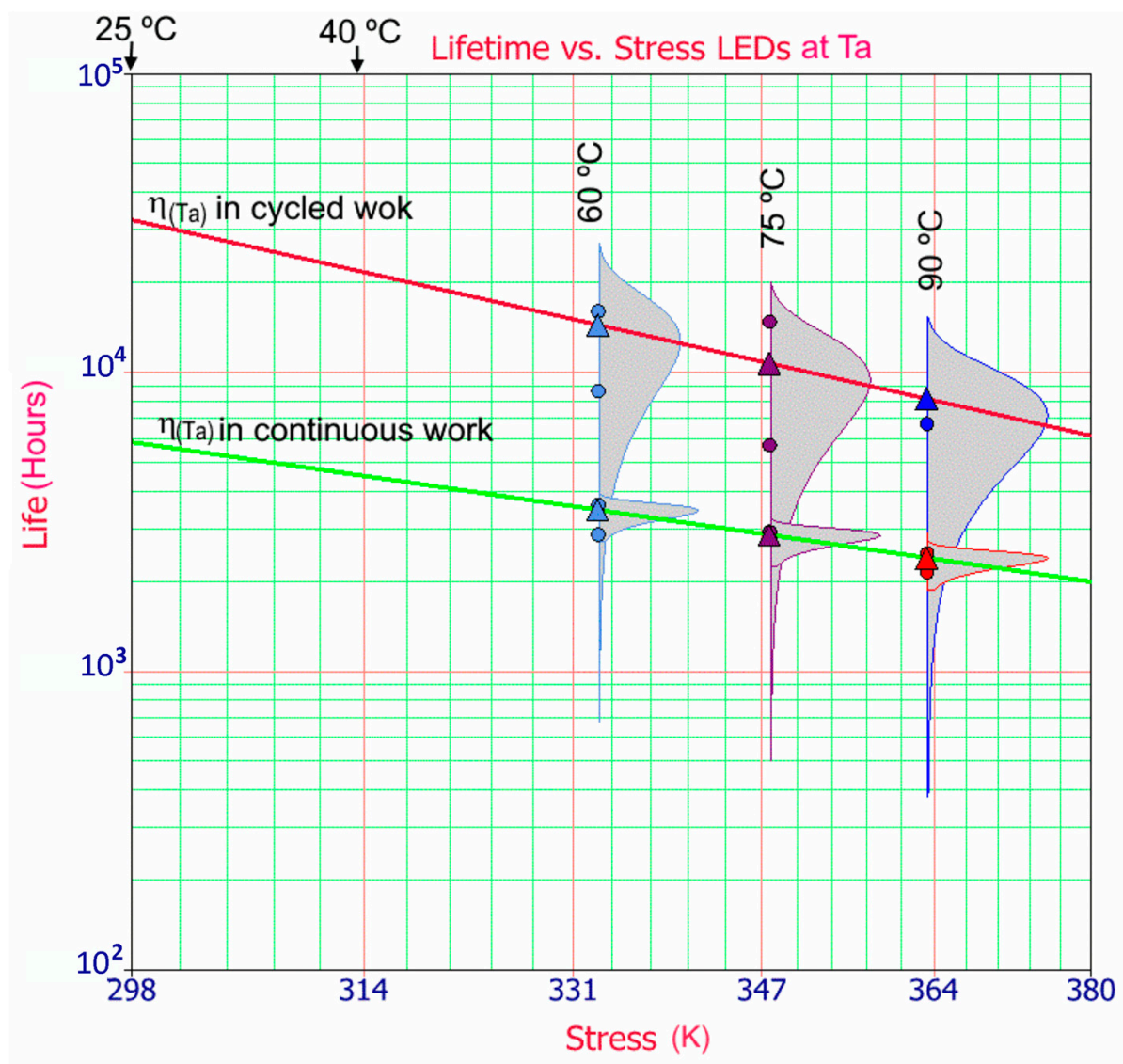

Figure 4. $f(t)$ probability density function of tested LEDs in three $\mathrm{T}_{\mathrm{a}}$ ALTs and two working conditions, indicated by gray areas. Evolution of $\eta_{(\mathrm{Ta})}$ Weibull parameter for continuous working indicated by the green line, and $\eta_{(\mathrm{Ta})}$ for cycled working ( $30 \mathrm{~s}$ on/30 s of) by the red line. Identification of $\eta_{(\mathrm{Ta})}$ at $\mathrm{T}_{\mathrm{a}}=25$ and $40{ }^{\circ} \mathrm{C}$ indicated by vertical dashed black lines.

The $F(t)$ unreliability function (probability of population failure at an instant) is as follows:

$$
F(t)=1-e^{-\left(\frac{t}{\eta_{(T j)}}\right)^{\beta}}
$$

$R(t)$ is reliability, the probability that the LED performs its function without failure:

$$
R(t)=e^{-\left(\frac{t}{\eta_{(T j)}}\right)^{\beta}}
$$

B50, where $50 \%$ of the population has no failure or survives, is obtained from (3) or (2), applying $R(B 50)=F(B 50)=0.5$.

The instant failure rate $\lambda(t)$ function is a conditional probability of the failure density function, simplifying the failure rate at an instant:

$$
\lambda(t)=\frac{f(t)}{R(t)}=\frac{\beta}{\eta_{(T j)}}\left(\frac{t}{\eta_{(T j)}}\right)^{\beta-1},
$$

The lifetime model applied in temperature ALT is the Arrhenius model [14]. This model is used for predicting semiconductor product lifetime in temperature ALTs, and relates the acceleration factor $\left(A_{F}\right)$ to any measurable temporal characteristic of the lifetime. $A_{F}$ is the ratio between any two lifetime 
parameters (for example, $\eta$, B50, MTTF or time for a $10 \%$ of accumulated population failures) at two $T_{j}$ working temperatures. $A_{F}$ is $>1$ if a low temperature is in the numerator, and is greater with the increase between both temperatures. From the Arrhenius model equation [14], the $A_{F}$ equation is defined with expression (5):

$$
A_{F}=\frac{\eta_{\left(T j \_ \text {Nominal }\right)}}{\eta_{\left(T j \_ \text {Stress }\right)}}=\exp \left[\frac{E_{A}}{k}\left(\left(\frac{1}{T_{j \_ \text {Nominal }}}\right)-\left(\frac{1}{T_{j \_ \text {Stress }}}\right)\right)\right],
$$

where $A_{F}$ is the acceleration factor obtained from (5), $E_{A}$ is the activation energy of the mechanism that causes degradation and ultimately failure, and $\mathrm{k}$ is the Boltzmann constant $\left(8.617333 \cdot 10^{-5} \mathrm{eV} / \mathrm{K}\right)$. $\eta_{\left(T j_{-} S t r e s s\right)}$ is the $\eta$ obtained for a $T_{j \_ \text {Stress }}$ ALT, and $\eta_{\left(T j_{-} \text {Nominal }\right)}$ for $T_{j \_ \text {Nomina }}$, usually the $T_{j}$ at nominal working conditions. As can be seen in Table 3, identifying the parameters of the Arrhenius-Weibull model corresponding to temperature ALTs implies knowledge of the lifetime values, and extrapolation to any other ambient temperature or thermal condition.

Table 3. Values of main lifetime parameters for ALT at $60{ }^{\circ} \mathrm{C}$ and evaluation results by the Arrhenius-Weibull model at nominal $\mathrm{T}_{\mathrm{a}}=40^{\circ} \mathrm{C} . \mathrm{T}_{j}$ is different for each $\mathrm{T}_{\mathrm{a}}$ and working condition.

\begin{tabular}{|c|c|c|c|c|c|}
\hline \multirow[b]{2}{*}{ Model } & \multirow[b]{2}{*}{ Parameter } & \multicolumn{2}{|c|}{$\mathrm{T}_{\mathrm{a}}=313 \mathrm{~K}\left(40^{\circ} \mathrm{C}\right)$} & \multicolumn{2}{|c|}{$\mathrm{T}_{\mathrm{a}}=333 \mathrm{~K}\left(\mathrm{ALT} 60^{\circ} \mathrm{C}\right)$} \\
\hline & & $\begin{array}{c}\text { Continuous Work } \\
T_{j}=331.5 \mathrm{~K}\end{array}$ & $\begin{array}{c}\text { Cycled Work } \\
T_{j}=327.5 \mathrm{~K}\end{array}$ & $\begin{array}{c}\text { Continuous Work } \\
T_{j}=351.5 \mathrm{~K}\end{array}$ & $\begin{array}{c}\text { Cycled Work } \\
T_{j}=347.5 \mathrm{~K}\end{array}$ \\
\hline Arrhenius & $E_{A}(\mathrm{eV})$ & $0.13 \pm 0.02$ & $0.20 \pm 0.02$ & $0.13 \pm 0.02$ & $0.20 \pm 0.02$ \\
\hline Weibull & $\beta$ & 16.6 & 3.1 & 16.6 & 3.1 \\
\hline Weibull & $\eta_{(T j)}(\mathrm{h})$ & 4588 & 22,301 & 3435 & 14,286 \\
\hline Weibull & $B 50_{(\mathrm{Tj})}(\mathrm{h})$ & 4488 & 19,814 & 3360 & 12,693 \\
\hline Weibull & $B 10_{(T j)}(\mathrm{h})$ & 4007 & 10,791 & 3000 & 6913 \\
\hline
\end{tabular}

From the optical power evolution of the LEDs and the degradation failure definition, the failure instant was assessed. With the data of the instant of LED failure versus temperature, and using specific Reliasoft ${ }^{\circledR}$ Weibull++/ALTA software and median ranks for failure populations, the software developed by MLE had the best adjustment of $\eta_{(\mathrm{Ta})}$ to the Arrhenius-Weibull model, restringing the same $\beta$ value to the three temperatures. As can be seen in Figure 4 , the time parameter $\eta_{(\mathrm{Ta})}$ has a good fit to a straight line, the slope of the line identifies the $E_{A}$ value of the tests, and in Table 3 there are complete parameters for $60^{\circ} \mathrm{C}$ evaluated by Equations (1)-(5) at $T_{j}$ nominal working conditions that suppose $\mathrm{T}_{\mathrm{a}}=40^{\circ} \mathrm{C}$.

Table 3 shows the Arrhenius-Weibull parameters and results for ALT at $\mathrm{T}_{\mathrm{a}}=333 \mathrm{~K}\left(\mathrm{~T}_{\mathrm{a}}=60{ }^{\circ} \mathrm{C}\right)$, and extrapolated at $\mathrm{T}_{\mathrm{a}}=313 \mathrm{~K}\left(\mathrm{~T}_{\mathrm{a}}=40^{\circ} \mathrm{C}\right)$, obtained using Equations (1)-(5). For each $\mathrm{T}_{\mathrm{a}}$ there is a different $T_{j}$ in each working condition, applying the temperature increments in Table 1.

The Arrhenius parameter activation energy $\left(E_{A}\right)$ evaluated is $0.13 \pm 0.02 \mathrm{eV}$ for the continuous and $0.20 \pm 0.02 \mathrm{eV}$ for the cycled working mode, showing different acceleration of failure times with temperature. The $A_{F}$ is $1.34 \pm 0.06$ for the continuous and $1.56 \pm 0.07$ for the cycled mode in the lifetime parameters for $\mathrm{T}_{\mathrm{a}}=40^{\circ} \mathrm{C}$, with respect to the evaluated conditions at $\mathrm{T}_{\mathrm{a}}=60^{\circ} \mathrm{C}$. Due to the uncertainty of $E_{A}$ and the minor effect of other parameters, the lifetime values B50 and B10 of Table 3 at $\mathrm{T}_{\mathrm{a}}=40^{\circ} \mathrm{C}$ have an uncertainty of $\pm 30 \%$. The errors were evaluated considering a confidence level of 0.85 . The $E_{A}$ values are low compared with the commonly used approximation for temperature ALT of $0.7 \mathrm{eV}$ [32], which supposes an $A_{F}=4.75$ for a decrement of $20^{\circ} \mathrm{C}$, but the two $E_{A}$ values obtained are common for this type of device.

The Weibull $\beta$ parameter is $>3$, which suggests that UV LEDs are in the wear-out failure phase of the bathtub curve [14] (pp. 90-91). This is very common for high current density stress semiconductors [15].

The values of time parameters ( $\eta$, B50) for cycled working are roughly four times larger than for continuous working, considering test time. Considering the net time of accumulating UV energy in cycled working, the lifetime is roughly double that of continuous work, so the difference is very significant. Furthermore, the increase in the lifetime UV LED in cycled working is mainly due to the 
electrical stress relaxation period between the on states, because the $T_{j}$ value, which is $4{ }^{\circ} \mathrm{C}$ less in cycled mode, does not justify that increase over the lifetime. Compared with UV-A lamps in natural convection, the lifetime in continuous working mode is like that of conventional UV-A lamps, and the lifetime in cycled working mode is better.

For an array of UV LEDs, B50 can be a suitable reference (50\% failure probability of the UV LED array), but is not the best parameter for applications with only one UV LED, such as sensing or microscopy, in which case $F(t)=10 \%$ with $\mathrm{t}=\mathrm{B} 10$ is a more realistic operation lifetime for replacement of the UV LED.

The Arrhenius-Weibull parameters are related to the failure modes [14] (pp. 90-91), and furthermore, to semiconductor materials and causes of encapsulation degradation, manufacturing processes, and stress. We analyzed whether the values of the evaluated parameters fit with the previous experience of UV-A LEDs; in general, UV LEDs are mainly grown on sapphire. There are several references to lifetime parameters $B 50_{(T j)}$ and MTTF [33-37], but almost no references to the other parameters, $\eta_{(T j)}, \beta$, and $E_{A},[17,33]$ :

The parameters $\eta_{(T j)}$ and $B 50_{(T j)}$ were in the range of previous reports on UV LEDs. In Rass et al.'s work [34], for low-power (100 mA) UV-B LEDs grown on sapphire substrates, an L70 limit failure was found for a $3500 \mathrm{~h}$ operation lifetime. These results in the same substrate are worse than the $4588 \mathrm{~h}$ for continuous working at $\mathrm{T}_{\mathrm{a}}=40^{\circ} \mathrm{C}$; in our case, the power is great but generally, a high wavelength of operation demonstrates the best efficiency and lifetime in UV LEDs. In Kurin et al.'s work [35], with $365 \mathrm{~nm}$ UV LEDs grown on $\mathrm{Al}_{2} \mathrm{O}_{3}$ substrate, the lifetime is $1850 \mathrm{~h}$ at $30^{\circ} \mathrm{C}$, working to $125 \mathrm{~A} / \mathrm{cm}^{2}$ and $0.5 \mathrm{~A}$. This work developed other substrates with a higher current density, offering a low lifetime compared with this commercial UV-A LED. In Mukai et al.'s work [36], for a standard manufactured GaN-based LED over GaN template of $365 \mathrm{~nm}, T_{j}=75^{\circ} \mathrm{C}$, and $120 \mathrm{~mW}$ (low power compared to our UV LED), an MTTF of 17,600 $\mathrm{h}$ was found. This is a really good result compared with our $365 \mathrm{~nm}$ commercial HP UV-A LED, but as we mentioned before, it is consistent with the bibliography, due to the fact that the GaN template has fewer dislocations than a sapphire template. In Reed et al.'s work [37], an improved cycled working is evaluated, and $280 \mathrm{~nm}$ LEDs at room temperature with $\mathrm{J}=300 \mathrm{~A} / \mathrm{cm}^{2}$ ( 6 times our J) had a lifetime of $20 \mathrm{~h}$ for continuous working and $1400 \mathrm{~h}$ in pulse conditions of $100 \mu \mathrm{s}$ and $1 \%$ cycle. Due to the reduction of self-heating, the lifetime relation is proximally proportional to the 99 times lower time that the LED operates in pulse conditions, as the accumulated operation time is critical for the lifetime. In Fujioka et al.'s work [38], the authors estimated an MTTF of $3000 \mathrm{~h}$ for a $280 \mathrm{~nm}$ UV-LED at $350 \mathrm{~mA}$, grown on a sapphire substrate at $T_{j}=30^{\circ} \mathrm{C}(303 \mathrm{~K})$. This LED has a similar working current at low wavelengths, but our estimated lifetime was considerably better, with great lifetime at $T_{j}=331.5 \mathrm{~K}$ versus the $303 \mathrm{~K}$ of this test.

The $E_{A}$ energy of the Arrhenius model is related to the temperature acceleration lifetime of the main failure mechanism; in this work, $E_{A}=0.13 \pm 0.02 \mathrm{eV}$ for the continuous mode. In Gong et al.'s work [39], $280 \mathrm{~nm}$ UV LEDs grown on a sapphire substrate working at $\mathrm{J}=100 \mathrm{~A} / \mathrm{cm}^{2}$ achieved an $\mathrm{eV}$ value of $0.23 \mathrm{eV}$. In Monti et al.'s work [17], with $385 \mathrm{UV}$ LEDs operating at $1 \mathrm{~A}, E_{A}=0.36 \mathrm{eV}$ was obtained. In Glaab et al.'s work [40], for $308 \mathrm{~nm}$ UV LEDs grown on an AlN/sapphire template, at ambient temperature with a high current $\left(75 / 150 / 225 \mathrm{~A} / \mathrm{cm}^{2}\right)$ applied, two time phase degradations were identified with two different activation energies: $0.13 \mathrm{eV}$ and $0.21 \mathrm{eV}$. These results for continuous working with a high-density current, mostly grown on sapphire, are coherent with our results.

\subsection{Evaluation of Lifetime Parameters in Forced Convection}

Table 3 shows the results of the evaluated lifetime parameters for $\mathrm{T}_{\mathrm{a}}=40^{\circ} \mathrm{C}$ and $\mathrm{ALT}$ at $\mathrm{T}_{\mathrm{a}}=60^{\circ} \mathrm{C}$ in natural convection. However, to compare the dissipation conditions on these tests, we must work with $T_{j}$ for each working condition and with its respective $E_{A}, \beta$, and $\eta_{(T j)}$. Equations (1)-(5) are applicable and more general using $T_{j}$, because the $T_{a}$ used as a reference is only a particularization for this UV LED setup in natural convection. 
In forced convection, there is a system with three elements: the UV LED, the fan, and the electronic circuit of the fan. We can reasonably simplify the system by combining the reliability of the electronic circuit and fan into one element, $R_{\text {Fan\&circuit }}(t)$, assuming from the reliability point of view that all elements are in series, and the failure of one element implies system failure.

The reliability $R(t)$ of the complete series system $R_{\text {LEDForce_System }}(t)$ is composed of the UV LED's $R_{L E D \_f o r c e d}(t)$ and the fan $R_{\text {Fan\&circuit }}(t)$. The result of the system is [14]:

$$
R_{\text {LEDForced_System }}(t)=R_{L E D_{-} \text {forced }}(t) \cdot R_{\text {Fan\&circuit }}(t),
$$

The $R(t)$ Weibull parameter of the subsystem $R_{\text {Fan\&circuit }}(t)$ is very specific, and we only have the information on the fan from its datasheet: $\mathrm{B} 10=40,000 \mathrm{~h}$ at $\mathrm{T}_{\mathrm{a}}=60^{\circ} \mathrm{C}$. Furthermore, the average parameter values for this subsystem at $\mathrm{T}_{\mathrm{a}}=40^{\circ} \mathrm{C}$ were considered; it can be seen in the works by Jin et al. [41] and Tian [42] that they are B10 $=50,000 \mathrm{~h}$ and $\beta=3$. From Equation (3), we can obtain $\eta=105,555 \mathrm{~h}$, and $\mathrm{B} 50=93,426$, which is a lifetime of roughly one decade, compared to the UV-A LED reliability.

Furthermore, the UV-A LED reliability is clearly the weak element of the chain; the only influence of the fan in the system reliability is the $T_{j}$ reduction. The $\beta$ and $E_{A}$ are the same for natural and forced convection, but $E_{A}$ is greater in cycled mode, as the influence of a decrement of temperature on the cycled working mode is more significant than in continuous mode. Furthermore, forced convection does not suppose a significant reduction with respect to the reliability of the isolated UV LED.

The increase in the time operation parameters $\left(\eta_{(T j)}, B 50_{(T j)}\right.$ and $\left.B 10_{(T j)}\right)$ in continuous working over natural convection at $\mathrm{T}_{\mathrm{a}}=40{ }^{\circ} \mathrm{C}$ is $4.6 \%$, and $7.7 \%$ for cycled mode. For example, the $\eta_{(T j)}$ at $\mathrm{T}_{\mathrm{a}}$ $=40^{\circ} \mathrm{C}$ values applied to the Weibull equation are $4803 \mathrm{~h}$ for continuous working and $24,020 \mathrm{~h}$ for cycled working.

In conclusion, for an isolated HP UV-LED with a good natural convection dissipation system, the addition of a high-reliability fan and circuit suppose less than a $10 \%$ lifetime increment, which does not justify the cost and increased complexity of the system. However, for industrial applications, an array of UV HP-LEDs is the solution, as the density power per area unit will be multiplied by four or more. In these cases, forced convection is necessary [43]. The reduction in $T_{j}$ over natural convection will be tens of degrees, and the lifetime could increase by more than double by applying the previous equations. In any case, the cycled working mode offers the best lifetime results.

\subsection{Failure Analysis}

As explained above, the only failure type of this GaN-based UV-A LED was progressive optical power degradation to under $70 \%$ of the initial optical power. This failure could be the consequence of one or a combination of physical causes.

To identify the causes, we analyzed the evolution of the I-V curve measured during tests under the same conditions $\left(\mathrm{T}_{\mathrm{a}}=25^{\circ} \mathrm{C}\right)$, the evolution of the optical power output and spectra, and the element's encapsulation integrity, observed by microscopy and measured by thermal tests.

From the analysis, the first general result is that the reference UV LED tested without current at $\mathrm{T}_{\mathrm{a}}=\mathrm{T}_{j}=90^{\circ} \mathrm{C}$ had insignificant degradation of the optical power output during the test, including in the I-V curve, and no silicone degradation. In conclusion, the optical degradation of the 12 working UV LEDs was caused by the working current in the semiconductor, and the UV radiation and thermal stress in the encapsulation [29].

In order to compare degradation in continuous and cycled working, it is necessary to note that the degradation process is slower in cycled working mode, because it takes half the time of real working and there is a relaxation of $T_{j}$ during the off state. In both working conditions, there are two contributors to degradation, but the observed effects in the cycled condition were delayed in the measurements.

To identify possible degradation of thermal conductivity of the whole system in natural convection (Figure 1a), the $T_{j}$ of the UV LEDs was measured at the beginning and end of the ALT. The results 
show that there was a small temperature increase, from 1 to $3{ }^{\circ} \mathrm{C}$, in $T_{j}$ due to loss of efficiency of the optical power. This suggests an increase in power dissipation for the same nominal current injection.

In Figure 5, the spectra evolution of the Led 75-1 working at $T_{a}=75^{\circ} \mathrm{C}$ and cycled mode can be seen. The wavelength peak shift due to aging is very low, with $0.78 \mathrm{~nm}$ of increase, and the initial value was $369.93 \mathrm{~nm}$. The break of silicone in this LED happened between $2215 \mathrm{~h}$ and $3500 \mathrm{~h}$, which explains the additional ratio decrease between both measurements.

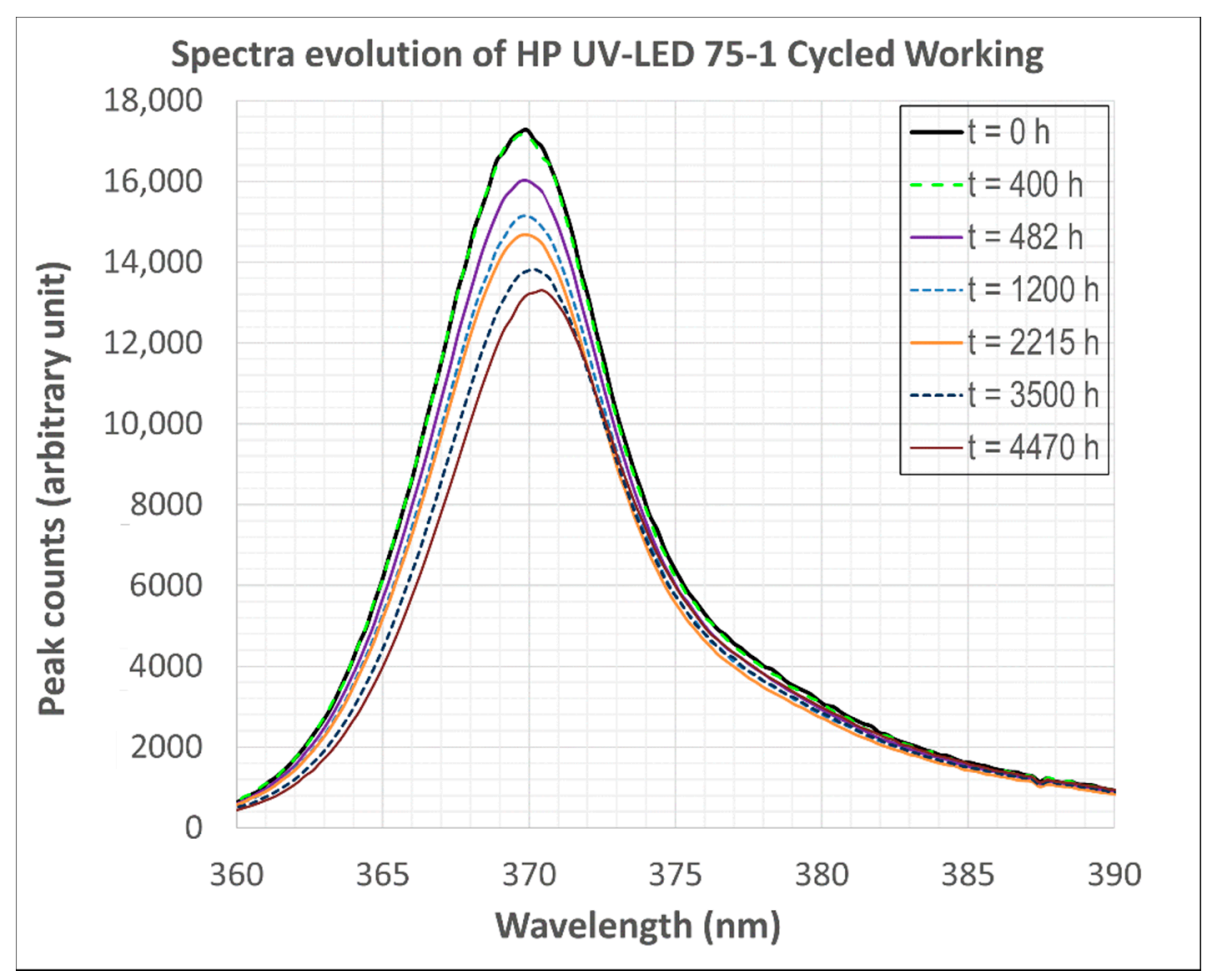

Figure 5. Graphic of the spectrometric wavelength versus time of UV-A LED 75-1 in cycled working mode at $\mathrm{T}_{\mathrm{a}}=75^{\circ} \mathrm{C}$.

The loss of measured optical power may be a consequence of semiconductor and/or encapsulation degradation. The main conclusion of the analysis was that there was a combination of both factors:

- The semiconductor device degradation was observed in the I-V curve time evolution during the tests, which started before the encapsulation silicone degradation.

- The encapsulation device degradation was observed by optical microscopy.

Figure 6 shows the different characterizations realized outside the climatic chamber at $25^{\circ} \mathrm{C}$. Figure 6a shows the I-V curve evolution in the ALT of UV LED 75-1 from Figure 3, tested at $T_{a}=75^{\circ} \mathrm{C}$ with cycled working; Figure $6 \mathrm{~b}$ shows the detailed I-V curve evolution of LED 75-1 in the nominal working condition with an injected current of $0.6 \mathrm{~A}$; Figure $6 \mathrm{c}$ shows the I-V curve evolution in the ALT of LED 75-3 tested at $\mathrm{T}_{\mathrm{a}}=75^{\circ} \mathrm{C}$ with continuous working; Figure $6 \mathrm{~d}$ shows a photograph of the final encapsulation condition of 75-1; and Figure 6e shows a photograph of the final encapsulation condition of 75-3.

The $\mathrm{I}-\mathrm{V}$ reverse curve evolution is limited because at $\mathrm{t}=0$ and during the test, the initial reverse curve and its evolution cannot be measured because a protection device mounted in the MCPCB circuit UV LED must be disassembled (Figure 1b). Only at the end of the ALTs of both UV LEDs and in new UV LEDs (Figure $6 \mathrm{a}, \mathrm{b} ; \mathrm{t}=0$ reverse) was the protection device disassembled, and the reverse current I-V curve measured. In these cases, the direction of the current was negative, but in the figure, it is represented as positive to allow the use of logarithmic axes. However, there was an evident increase in reverse current in both cases, which was larger in the case of continuous working. 


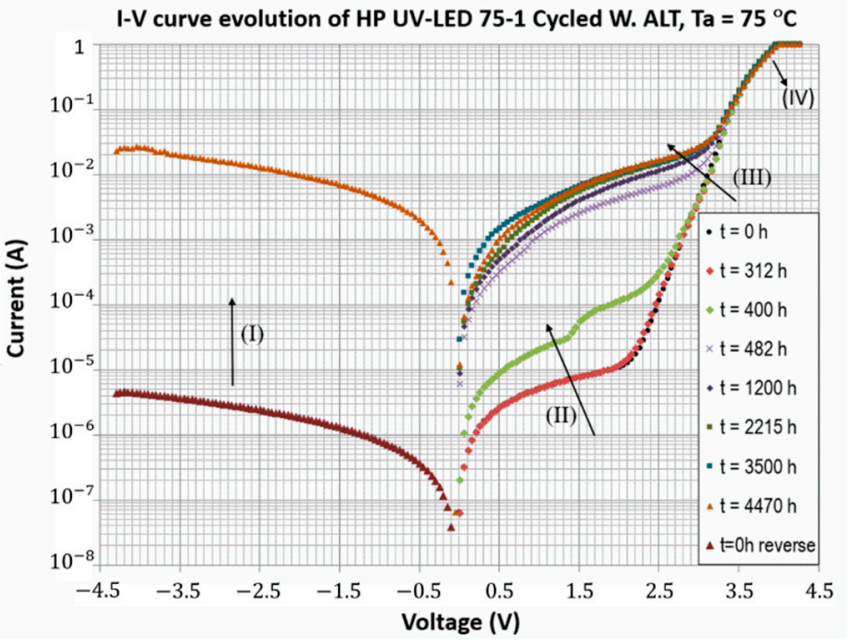

(a)

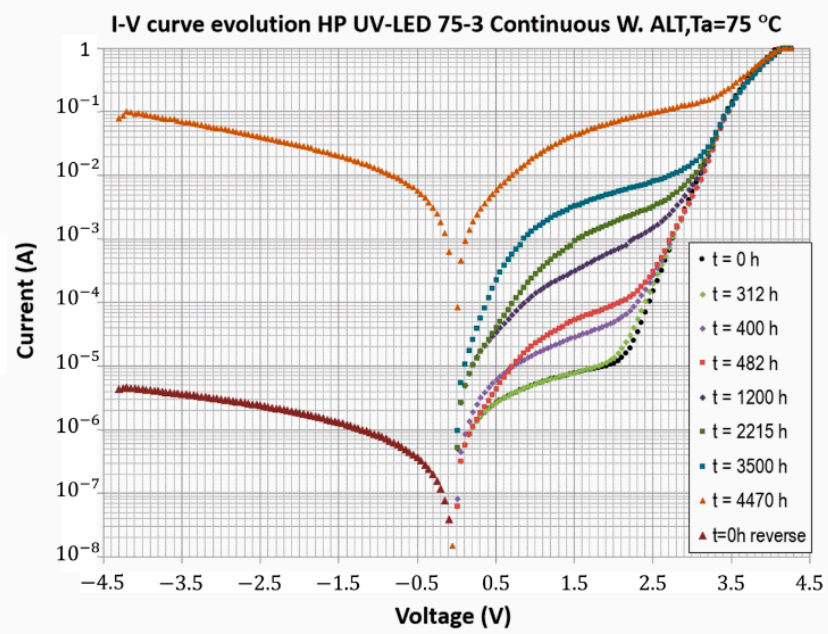

(c)

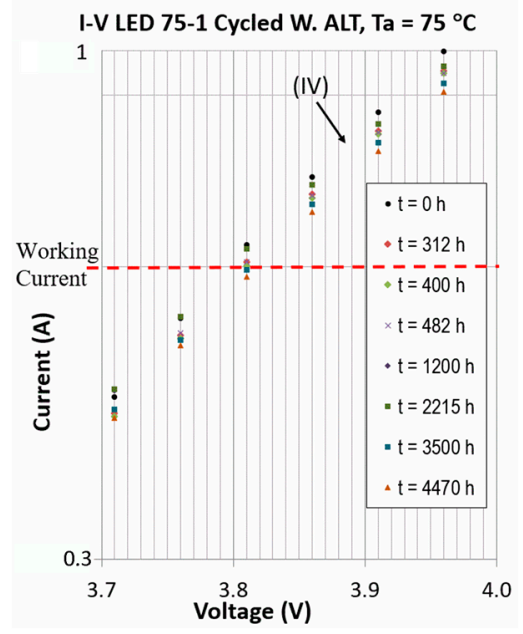

(b)

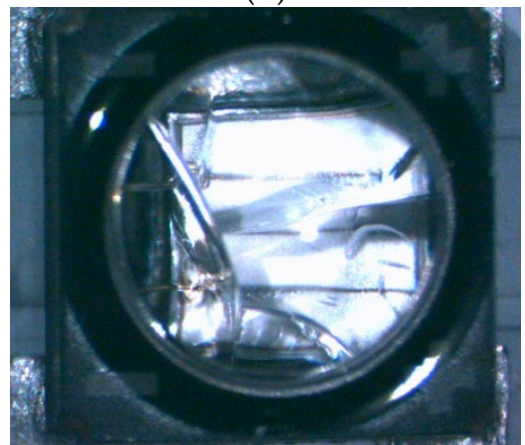

(d)

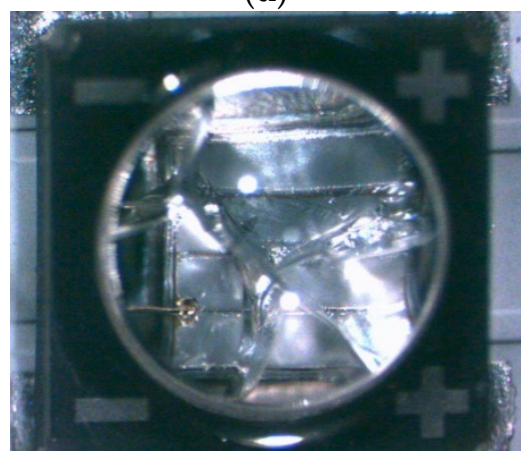

(e)

Figure 6. Test results measured outside the climatic chamber at $\mathrm{T}_{\mathrm{a}}=25^{\circ} \mathrm{C}$. (a) $\mathrm{I}-\mathrm{V}$ curve evolution in ALT of UV LED 75- 1 of Figure 3, tested at $\mathrm{T}_{\mathrm{a}}=75^{\circ} \mathrm{C}$ with cycled working; (b) detailed I-V curve evolution of LED 75-1 with the nominal working condition $0.6 \mathrm{~A}$; (c) I-V curve evolution in ALT of UV LED 75-3 of Figure 3, tested at $\mathrm{T}_{\mathrm{a}}=75^{\circ} \mathrm{C}$ with continuous working; (d) photograph of cycled working LED 75-1 encapsulation at the end of ALT; (e) photograph of continuous working LED 75-3 encapsulation at the end of ALT.

The I-V curve evolution of cycled and working UV LEDs was similar, but in cycled working it was smaller and delayed, with less final reverse bias and less degraded forward bias, in part because of the cycled working mode having half the real operation time and the minor $T_{j}$ of the semiconductor. The evolution was the same in equivalent UV LEDs tested at 60 and $90{ }^{\circ} \mathrm{C}$.

From the curve analysis, it is possible to identify that both reverse bias and forward bias increased over time (Figure 6) due to the degradation of the diode semiconductor characteristics, and that this affected the optical power efficiency, which decreased with time (Figure 3). This is a common issue in UV LEDs ALTs based on four characteristic regions in the curve $[15,17,32,39,43,44]$. In Figure 6a,c, 
the high reverse bias leakage current of UV LEDs in region I can be attributed to defects or threading dislocations in the active region, which form parasitic current paths and a short active region $[19,39,44]$, because leakage current has a quadratic dependence on dislocation density [44]. Region II represents low forward bias and increased generation-recombination current, mainly determined by parallel resistance, which is degraded by dislocations. Region III represents an increase in the device's ideality factor. Region IV represents an increase in parasitic series resistance RS (Figure 6b) [15,17,32,43-45], which can be attributed to either degradation of the contact metal, contact wire bonding, or the degradation of the semi-transparent ohmic contact on top of the p-layer [3,46].

Using optical microscopy, an analysis of encapsulation was performed. We identified from Figure $6 \mathrm{~d}$,e that there was no yellowing of the silicone when the temperature ALT finished. Silicone was selected due to its good UV transparency and thermal resistance [33]. However, thermal and UV radiation conditions over the semiconductor are aggressive, and consequently there has been evident silicone package cracking and delamination observed in several studies $[23,29,47]$. In Figure 6d,e, it can be seen that the cracking originated in the wire bonding, and the origin time depended on real accumulated working time and temperature. The cracks occurred earlier and the evolution was worse in higher temperatures for continuous working mode with respect to the cycled working mode, as can be seen in Figure 6. This evolution was similar to the results and time evolution in work [29]. The cracks produced a loss of transparency and an important reflection of emitted light in the encapsulation, suggesting a decrease in the optical power.

It is difficult to identify the weight of every type of degradation in the total optical power, because there is also feedback between them. Lower silicon quality results in less transparency, more reflections, and high autoheating, which increases semiconductor degradation, leading to worse power efficiency and more autoheating. Resolving one or both degradation sources will have a cumulative effect on the improvement of total degradation.

In the case of silicone degradation, there was an important conclusion at the end the of $\mathrm{T}_{\mathrm{a}}=60^{\circ} \mathrm{C}$ test. In this case, both types of working produced I-V curve degradation, but optical microscopy silicone degradation only appeared in continuous working; in cycled working, only semiconductor degradation was found. Comparing degradation types, we can conclude that the main source of optical power degradation is the device semiconductor, and the second is the silicone break.

\section{Conclusions}

This work analyzes, by temperature ALT, the lifetime characteristics of a high-quality commercial GaN-based HP UV-A LED. The analysis was carried out for two dissipation convection conditions, natural and force, and two working modes, continuous and cycled.

The lifetime of the LED is strongly linked with the technology and manufacturing process of the specific device; therefore, it is not possible to extrapolate a strictly quantitative lifetime of this HP UV-A LED to all commercial UV-A LEDs. However, these quantitative results offer clues to the expected lifetime of GaN-based HP UV-A LEDs in the analyzed working and dissipation conditions.

Furthermore, the main qualitative results and conclusions can be generalized.

The device, encapsulation, and setup of temperature ALT and $T_{j}$ semiconductor working conditions in natural convection were measured (Figure 2), and compared in terms of relative and absolute values (Table 1).

The work was focused on three objectives. First, to assess the lifetime equations (Equations (1)-(5)) for evaluating the lifetime and probability of life expectancy in any environmental conditions; to resolve these equations, it is necessary to use the Arrhenius and Weibull parameters (Table 3) obtained in the temperature ALTs results (Table 2, Figures 3-5). Second, to compare in equivalent conditions the lifetime under continuous and cycled working in natural convection (Table 3) and forced convection, identify the best lifetime conditions, and propose improvements. Third, to identify the causes of failure and reach conclusions to improve the lifetime.

The main conclusions of this work are as follows: 
- The real-time operation and junction temperature of the semiconductor during operation are critical for the lifetime. Higher $T_{j}$ and continuous real-time operation result in high degradation of the optical power. The cycled mode has the best lifetime values, because the intermittent time produces a $T_{j}$ relaxation and there is a significant decrease in the maximum $T_{j}$ with respect to continuous working. The curves of normalized optical power evolution show that there is more than double the degradation in continuous compared to cycle mode, which needs to operate doubly for the same working real-time (Figure 3).

- The advantage of cycled mode is evident for cycled or punctual UV applications such as microscopy. For many industrial applications where accumulated UV-A energy is required, it is necessary to consider that cycle mode doubles the time required.

- The Arrhenius-Weibull parameters were evaluated in tests under nominal convection, and extrapolated by analyzing the complete system in forced convection. The use of these equations is mandatory because the evolution of degradation is not linear with time.

- The activation energy $\left(E_{A}\right)$ was $0.13 \pm 0.02 \mathrm{eV}$ for continuous and $0.20 \pm 0.02 \mathrm{eV}$ for cycled work, with a value of $\beta>3$; this indicates that the UV LEDs had increased degradation over time. Due to this, the lifetime under continuous working at $T_{a}=40^{\circ} \mathrm{C}$ was $4000 \mathrm{~h}$ at $\mathrm{B} 10(10 \%$ of UV LED failure) and $4488 \mathrm{~h}$ at B50, which are very similar values. In cycled mode, the values were $\mathrm{B} 10=5396 \mathrm{~h}$ and $\mathrm{B} 50=9907 \mathrm{~h}$, showing a bigger difference.

- Equations for evaluating the reliability of the system with forced convection were developed, and the increase in lifetime was evaluated. We found an additional $4.6 \%$ lifetime for continuous working mode, and $7.7 \%$ for cycled mode. This is negligible considering the increase in cost and complexity. However, for HP LED arrays, forced convection is mandatory due to the need to obtain tens of hundreds of watts of power in a small area, and a reduction of $T_{j}$ that consequently increases lifetime will be very relevant.

- In the failure analysis, one mode of failure was identified, optical power degradation below $70 \%$ of the initial value, and two causes of this failure; semiconductor device degradation observed in the I-V curve time evolution during the test, and silicon encapsulation degradation observed by optical microscopy.

Improving GaN-based growth substrate technology and encapsulation materials is the main objective in order to substantially increase the lifetime of HP UV-A LEDs.

For current commercial HP UV-A LED technology, the lifetime improves with lower $T_{j}$ values, and this is possible with the cycled working mode and good natural or forced dissipating systems. The current UV-A LED lifetime is comparable to or better than that of UV-A lamps when good thermal management is used. In cycled working mode, the net real working lifetime is over 10,000 $\mathrm{h}$ for B50L70; there was $50 \%$ population failure below $70 \%$ of the original optical power.

Author Contributions: Conceptualization, F.J.A.-O., M.V. and N.N.; methodology, software, and validation, F.J.A.-O. and N.N.; investigation, resources, and data curation F.J.A.-O., M.V. and N.N.; writing-original draft preparation, F.J.A.-O. and N.N.; writing-review and editing, M.V. and N.N.; visualization, M.V.; supervision, F.J.A.-O. and N.N.; project administration and funding acquisition, F.J.A.-O. All authors have read and agreed to the published version of the manuscript.

Funding: This research received no external funding.

Acknowledgments: The Water Authority of the Tagus River (Spain) assisted in this study by making its laboratory available for testing, as well as providing support and knowledge.

Conflicts of Interest: The authors declare no conflict of interest. 


\section{References}

1. Muramoto, Y.; Kimura, M.; Nouda, S. Development and future of ultraviolet light-emitting diodes: UV-LED will replace the UV lamp. Semicond. Sci. Technol. 2014, 29, 084004. [CrossRef]

2. Dreyer, C.; Mildner, F. Application of LEDs for UV-curing. In III-Nitride Ultraviolet Emitters; Kneissl, M., Rass, J., Eds.; Springer: Cham, Switzerland, 2016; pp. 415-434.

3. Nagasawa, Y.; Hirano, A. A Review of AlGaN-Based Deep-Ultraviolet Light-Emitting Diodes on Sapphire. Appl. Sci. 2018, 8, 1264. [CrossRef]

4. Brault, J.; Damilano, B.; Leroux, M.; Courville, A.; Chenot, S.; Randazzo, G.; Vennéguès, P.; DeMierry, P.; Massies, J.; Rosales, D.; et al. AlGaN/GaN nanostructures for UV light emitting diodes. In Proceedings of the Asia Communications and Photonics Conference, Shanghai, China, 11-14 November 2014; pp. 11-13. [CrossRef]

5. Hamamatsu. Xenon Lamp, Xenon Flash Lamp, Mercury-Xenon Lamp, Deuterium Lamp and Hollow Cathode Lamp. Section Life. Available online: https://www.hamamatsu.com/resources/pdf/etd/LIGHT_ SOURCE_TLSZ0001E.pdf (accessed on 20 September 2020).

6. Mukish, P.; Boulay, P.; Vallo, M. Status of the Solid-State Lighting Source Industry 2019-Yole Développement—Sample. Available online: https://s3.i-micronews.com/uploads/2019/07/YD19033_Statusof-SSL-Source-Industry-2019_Yole_Sample.pdf (accessed on 20 September 2020).

7. Khan, A.; Balakrishnan, K.; Katona, T. Ultraviolet light-emitting diodes based on group three nitrides. Nat. Photonics 2008, 2, 77-84. [CrossRef]

8. Matafonova, G.; Batoev, V. Recent advances in application of UV light-emitting diodes for degrading organic pollutants in water through advanced oxidation processes: A review. Water Res. 2018, 132, 177-189. [CrossRef] [PubMed]

9. Arques-Orobon, F.J.; Nuñez, N.; Vazquez, M.; Gonzalez-Posadas, V. Functional analysis in long-term operation of high power UV-LEDS in continuous fluoro-sensing systems for hydrocarbon pollution. Sensors 2016, 16, 293. [CrossRef]

10. Pirc, M.; Caserman, S.; Ferk, P.; Topič, M. Compact uv led lamp with low heat emissions for biological research applications. Electronics 2019, 8, 343. [CrossRef]

11. Prasad, A.; Gänzle, M.; Roopesh, M.S. Inactivation of Escherichia coli and Salmonella using 365 and $395 \mathrm{~nm}$ high intensity pulsed light emitting diodes. Foods 2019, 8, 679. [CrossRef]

12. IESNA LM-80-08-IES Approved Method: Measuring Lumen Maintenance of LED Light Sources. Available online: https://webstore.ansi.org/standards/iesna/iesnalm8008 (accessed on 20 September 2020).

13. ANSI/IES RP-16-10 Nomenclature and Definitions for Illuminating Engineering-Illuminating Engineering Society. Available online: https://www.ies.org/lda/ansiies-rp-16-10-nomenclature-and-definitions-forilluminating-engineering/ (accessed on 20 September 2020).

14. Tobias, P.; Trindade, D. Applied Reliability, 3rd ed.; CRC Press: Boca Raton, FL, USA, 2011.

15. Pinos, A.; Marcinkevičius, S.; Shur, M.S. High current-induced degradation of AlGaN ultraviolet light emitting diodes. J. Appl. Phys. 2011, 109, 103108. [CrossRef]

16. Li, J.; Zhang, G.Q. Light-Emitting Diodes: Materials, Processes, Devices and Applications; Springer: Beijing, China, 2018; ISBN 978-3-319-99210-5.

17. Monti, D.; Meneghini, M.; De Santi, C.; Meneghesso, G.; Zanoni, E. Degradation of UV-A LEDs: Physical Origin and Dependence on Stress Conditions. IEEE Trans. Device Mater. Reliab. 2016, 16, $213-219$. [CrossRef]

18. Van Driel, W.D.; Fan, X.J. Solid State Lighting Reliability: Components to Systems; Springer: New York, NY, USA, 2013; ISBN 9781461430674.

19. Chen, S.W.; Chang, C.J.; Lu, T.C. Effect of strains and v-shaped pit structures on the performance of gan-based light-emitting diodes. Crystals 2020, 10, 311. [CrossRef]

20. Matsumoto, T.; Ajmal Khan, M.; Maeda, N.; Fujikawa, S.; Kamata, N.; Hirayama, H. Milliwatt power UV-A LEDs developed by using n-AlGaN superlattice buffer layers grown on AlN templates. J. Phys. D. Appl. Phys. 2019, 52, 4-6. [CrossRef]

21. Orlando, V.; Gabás, M.; Galiana, B.; Espinet-González, P.; Palanco, S.; Nuñez, N.; Vázquez, M.; Araki, K.; Algora, C. Failure analysis on lattice matched GaInP/Ga(In)As/Ge commercial concentrator solar cells after temperature accelerated life tests. Prog. Photovolt. Res. Appl. 2017, 25, 97-112. [CrossRef] 
22. Nunez, N.; Vazquez, M.; Barrutia, L.; Bautista, J.; Lombardero, I.; Zamorano, J.C.; Hinojosa, M.; Gabas, M.; Algora, $\mathrm{C}$. Innovative Temperature Accelerated Life Test for the determination of the activation energy of space solar cells. In Proceedings of the ESPC 2019, Juan-Les-Pins, France, 30 September-4 October 2019. [CrossRef]

23. Liang, B.; Wang, Z.; Qian, C.; Ren, Y.; Sun, B.; Yang, D.; Jing, Z.; Fan, J. Investigation of step-stress accelerated degradation test strategy for ultraviolet light emitting diodes. Materials 2019, 12, 3119. [CrossRef]

24. Yang, X.; Sun, B.; Wang, Z.; Qian, C.; Ren, Y.; Yang, D.; Feng, Q. An alternative lifetime model for white light emitting diodes under thermal-electrical stresses. Materials 2018, 11, 817. [CrossRef]

25. Qian, C.; Fan, J.; Fang, J.; Yu, C.; Ren, Y.; Fan, X.; Zhang, G. Photometric and colorimetric assessment of LED chip scale packages by using a step-stress accelerated degradation test (SSADT) method. Materials 2017, 10, 1181. [CrossRef] [PubMed]

26. Davididou, K.; McRitchie, C.; Antonopoulou, M.; Konstantinou, I.; Chatzisymeon, E. Photocatalytic degradation of saccharin under UV-LED and blacklight irradiation. J. Chem. Technol. Biotechnol. 2018, 93, 269-276. [CrossRef]

27. Havia, J.; Niemelä, M.; Perämäki, P. Nano-TiO 2 catalyzed UV-LED sample pretreatment method for decomposition of humic substances in natural water samples. Microchem. J. 2017, 133, 645-649. [CrossRef]

28. Erickstad, M.; Gutierrez, E.; Groisman, A. A low-cost low-maintenance ultraviolet lithography light source based on light-emitting diodes. Lab Chip 2015, 15, 57-61. [CrossRef]

29. Arques-Orobon, F.J.; Nuñez, N.; Vazquez, M.; Segura-Antunez, C.; González-Posadas, V. High-power UV-LED degradation: Continuous and cycled working condition influence. Solid State Electron. 2015, 111, 111-117. [CrossRef]

30. Vázquez, M.; Núñez, N.; Nogueira, E.; Borreguero, A. Degradation of AlInGaP red LEDs under drive current and temperature accelerated life tests. Microelectron. Reliab. 2010, 50, 1559-1562. [CrossRef]

31. Ryu, H.Y.; Ha, K.H.; Chae, J.H.; Nam, O.H.; Park, Y.J. Measurement of junction temperature in GaN-based laser diodes using voltage-temperature characteristics. Appl. Phys. Lett. 2005, 87, 1-4. [CrossRef]

32. Bayle, F.; Mettas, A. Temperature acceleration models in reliability predictions: Justification \& improvements. In Proceedings of the Annual Reliability and Maintainability Symposium, San Jose, CA, USA, 25-28 January 2010; pp. 1-6. [CrossRef]

33. De Santi, C.; Monti, D.; Dalapati, P.; Meneghini, M.; Meneghesso, G.; Zanoni, E. Reliability of Ultraviolet Light-Emitting Diodes; Springer: Cham, Switzerland, 2019; pp. 397-424.

34. Rass, J.; Kolbe, T.; Lobo-Ploch, N.; Wernicke, T.; Mehnke, F.; Kuhn, C.; Enslin, J.; Guttmann, M.; Reich, C.; Mogilatenko, A.; et al. High-power UV-B LEDs with long lifetime. In Proceedings of the Gallium Nitride Materials and Devices X, San Francisco, CA, USA, 9-12 February 2015; Chyi, J.-I., Fujioka, H., Morkoç, H., Eds.; SPIE: Bellingham, WA, USA, 2015; Volume 9363, p. 93631K. [CrossRef]

35. Kurin, S.; Antipov, A.; Barash, I.; Roenkov, A.; Helava, H.; Tarasov, S.; Menkovich, E.; Lamkin, I.; Makarov, Y. CHVPE growth of AlGaN-based UV LEDs. Phys. Status Solidi Curr. Top. Solid State Phys. 2013, 10, $289-293$. [CrossRef]

36. Mukai, T.; Morita, D.; Yamamoto, M.; Akaishi, K.; Matoba, K.; Yasutomo, K.; Kasai, Y.; Sano, M.; Nagahama, S. Investigation of optical-output-power degradation in 365-nm UV-LEDs. Phys. Status Solidi 2006, 3, 2211-2214. [CrossRef]

37. Reed, M.L.; Wraback, M.; Lunev, A.; Bilenko, Y.; Hu, X.; Sattu, A.; Deng, J.; Shatalov, M.; Gaska, R. Device self-heating effects in deep UV LEDs studied by systematic variation in pulsed current injection. Phys. Status Solidi 2008, 5, 2053-2055. [CrossRef]

38. Fujioka, A.; Asada, K.; Yamada, H.; Ohtsuka, T.; Ogawa, T.; Kosugi, T.; Kishikawa, D.; Mukai, T. High-output-power 255/280/310 nm deep ultraviolet light-emitting diodes and their lifetime characteristics. Semicond. Sci. Technol. 2014, 29, 084005. [CrossRef]

39. Gong, Z.; Chhajed, S.; Gaevski, M.E.; Sun, W.H.; Adivarahan, V.; Shatalov, M.; Khan, M.A. Reliability and Degradation Modes of 280 nm Deep UV LEDs on Sapphire; Cambridge University Press: Cambridge, UK, 2006; Volume 892, pp. 169-174.

40. Glaab, J.; Ploch, C.; Kelz, R.; Stölmacker, C.; Lapeyrade, M.; Ploch, N.L.; Rass, J.; Kolbe, T.; Einfeldt, S.; Mehnke, F; et al. Degradation of (InAlGa)N-based UV-B light emitting diodes stressed by current and temperature. J. Appl. Phys. 2015, 118, 094504. [CrossRef] 
41. Jin, X.; Ma, E.W.M.; Chow, T.W.S.; Pecht, M. An investigation into fan reliability. In Proceedings of the IEEE 2012 Prognostic and System Health Management Conference (PHM-2012), Beijing, China, 23-25 May 2012; pp. 1-7. [CrossRef]

42. Tian, X. Cooling fan reliability: Failure criteria, accelerated life testing, modeling and qualification. In Proceedings of the Annual Reliability and Maintainability Symposium, Newport Beach, CA, USA, 23-26 January 2006; pp. 380-384. [CrossRef]

43. Hölz, K.; Lietard, J.; Somoza, M.M. High-Power 365 nm UV LED Mercury Arc Lamp Replacement for Photochemistry and Chemical Photolithography. ACS Sustain. Chem. Eng. 2017, 5, 828-834. [CrossRef]

44. Moon, S.-M.; Kwak, J. High-current Electro-optical Degradation of InGaN/GaNLight-emitting Diodes Fabricated with Ag-based Reflectors. J. Korean Phys. Soc. 2009, 55, 1128-1131. [CrossRef]

45. Lee, S.W.; Oh, D.C.; Goto, H.; Ha, J.S.; Lee, H.J.; Hanada, T.; Cho, M.W.; Yao, T.; Hong, S.K.; Lee, H.Y.; et al. Origin of forward leakage current in GaN-based light-emitting devices. Appl. Phys. Lett. 2006, 89, 132117. [CrossRef]

46. Meneghesso, G.; Levada, S.; Zanoni, E.; Podda, S.; Mura, G.; Vanzi, M.; Cavallini, A.; Castaldini, A.; Du, S.; Eliashevich, I. Failure Modes and Mechanisms of DC-Aged GaN LEDs. Phys. Status Solidi 2002, 194, 389-392. [CrossRef]

47. Kim, H.-Y.; Lee, J.-W.; Jun, D.-J.; Song, S.-J.; Oh, J.-T.; Jeong, H.-H.; Seong, T.-Y.; Amano, H. Effects of Ultraviolet Wavelength and Ambient Temperature on Reliability of Silicones in InAlGaN-Based Light-Emitting-Diode Package. ECS J. Solid State Sci. Technol. 2020, 9, 035005. [CrossRef]

Publisher's Note: MDPI stays neutral with regard to jurisdictional claims in published maps and institutional affiliations. 